\title{
Phase II study of Epirubcin, Cisplatin and Capecitabine as Neoadjuvant chemotherapy for resectable gastric and gastroesophageal junction cancer
}

\author{
Mohamed El. Bassiouny, Reda Moustafa ${ }^{1}$, Ashraf Abdel Moghny ${ }^{1}$ and ahmed Eltaweel ${ }^{2}$ \\ Deparment of Clinical Oncology and Nuclear Medicine, Ain Shams University. ${ }^{1}$ Department of General \\ Surgery, Ain Shams University. ${ }^{2}$ Department of Pathology, Ain Shams University.
}

\begin{abstract}
Purpose: This phase II study was performed to investigate the efficacy and safety of this combination in treatment of patients with resectable gastric cancer.

Background: The majority of gastric cancer patients present with advanced, incurable disease and only a minority have localised disease that is suitable for radical treatment. A benefit has generally been demonstrated from adding chemotherapy to surgery for early disease though there are marked differences in how this is done globally. The regimen of epirubicin, cisplatin, and infused fluorouracil (ECF), achieves response rates between 49 percent and 56 percent in randomized trials of the treatment of locally advanced gastric cancer. The present trial was designed to determine whether a regimen of epirubcin, cisplatin and capecitabine (ECC) given before radical surgery improves the outcomes of operable gastric cancer. Our aim was to evaluate the neoadjuvant chemotherapy for patients with resectable gastric cancer in term of efficacy and toxicity.
\end{abstract}

Patients and Methods: In this phase II study, Patients of any age who had a World Health Organization (WHO) performance status of 0 or 1 were eligible if they had histologically proven adenocarcinoma of the stomach or gastroesophagal junction that was considered to be stage II (through the submucosa) or higher, with no evidence of distant metastases, or locally advanced inoperable disease. patients were treated with three cycles of preoperative ECC (epirubicin, cisplatin and capecitabine), Epirubicin was given in a dose of $50 \mathrm{mg} / \mathrm{m}^{2}$ on day 1 intravenously every 3 weeks immediate prior to the cisplatin, which was administered at a dose of $60 \mathrm{mg} / \mathrm{m}^{2}$ on day 1 intravenously every 3 weeks with hydration. Capecitabine was given orally in two equally divided doses, $1000 \mathrm{mg} / \mathrm{m}^{2}$ bid with a meal or snack from day 1-14 every 3 week. followed by surgery with adequate lymph node dissection, our primary endpoint was toxicity and secondary end point was prediction of response.

Results: A total of 25 patients were evaluated by intention-to-treat analysis for efficacy and safety. The overall response rate (ORR) was 59\% (complete and partial response, 13.6\% and 45.4\%, respectively). Nonhematological toxicity $(96 \%)$ was more common than hematological toxicity $(28 \%)$. Severe hematological toxicity was rare $(4 \%)$.

Conclusion: In patients with operable gastric and gastroesophageal junction cancer a neoadjuvant regimen of ECC decreased tumor size and stage with good tolerability and safety profile.

Key words: epirubcin, cisplatin, capecitabine, neoadjuvant, resectable gastric cance

Corresponding Author: ????????????????

E-mail: ???????????????????????????

\section{INTRODUCTION}

Gastric cancer is the fourth most common cancer in the world with an annual incidence of approximately one million ${ }^{1}$. In the UK, there are an estimated 7,700 new diagnoses and 5,200 deaths from the disease each year ${ }^{2}$. Over the past two decades there has been a change in the anatomical subsite distribution of gastric cancer, with a trend for tumours to develop more in the proximal stomach, especially around the gastric cardiac area rather than the distal part of the stomach ${ }^{3}$. It is thought that the lower oesophageal tumours may also be associated with an increasing incidence of gastro-oesophageal reflux disease ${ }^{4}$. In spite of a declining incidence of the distal stomach cancer in the Western countries over the past decades, the incidence of adenocarcinoma of the lower esophagus and the gastroesophageal junction has dramatically increased in the world ${ }^{5}$. Early-stage gastric and gastroesophageal cancers are curable with surgical treatment alone, with a 5-year overall survival rate of $90 \%$. However, the majority of gastric and gastroesophageal cancer patients are diagnosed with advanced diseases (stages III or IV) ${ }^{6}$.

Despite advances in cancer management, gastric cancer continues to remain a challenging disease to 
treat. Almost one million new cases and over 738,000 deaths occur from gastric cancer every year, making it the fourth most common malignancy and second most common cause of cancer related death in the world ${ }^{7}$. A marked geographical variation exists, with more than $70 \%$ of cases occurring in developing countries and majority being in Eastern Asia ${ }^{7}$. In the Western world gastric cancer is often diagnosed at an advanced stage, in contrast to Japan where patients are more commonly diagnosed at an early stage probably due to an established gastric cancer screening program ${ }^{8}$. Radical surgery is the only modality that can lead to potential cure for localised disease however most patients will relapse post curative resection with locoregional or metastatic disease leading to poor overall survival $^{9,10}$. Various multimodality approaches using chemotherapy, radiation or a combination of both have been evaluated in the last few decades in an attempt to improve outcomes post surgery.

Although adjuvant chemotherapy has demonstrated improved survival from gastric cancer, it is challenging to use it in most patients. Often post major surgery such as total gastrectomy, there can be long delays before patients are fit enough to start adjuvant chemotherapy, thus a number of patients are unable to have any post operative treatment, potentially leaving behind untreated micro-metastatic disease. Therefore, neoadjuvant chemotherapy has also been evaluated in gastric cancer as in general, it is much better tolerated than adjuvant chemotherapy, leading to a greater proportion of patients being able to have systemic treatment ${ }^{11}$. Additionally, the usage of neoadjuvant chemotherapy may lead to downsizing of the tumour which may facilitate a curative resection in a greater proportion of patients. With this in mind, the EORTC 40954 study $(\mathrm{n}=144)$ evaluated the role of neoadjuvant chemotherapy in early gastric cancer however, the trial was closed early due to poor accrual ${ }^{12}$. An increased rate of R0 resection was seen $(81.9 \%$ versus $66.7 \%, P$ $=0.036$ ) with the use of neoadjuvant chemotherapy but this did not translate into a benefit in overall survival (hazard ratio, 0.84; 95\% CI, 0.52-1.35; $P=.466$ ). Given the lack of supporting data, at this stage a purely neoadjuvant chemotherapeutic strategy should not be used in early gastric cancer.

The TNM staging classification dictates the subsequent management of a gastric tumour. Primary resection of the malignant tumour is the standard treatment for operable disease. In the Western world, most patients with gastric cancer present with advanced stages of disease, leading to a low 5-year survival of around $25 \%{ }^{7,8}$. After surgical resection, the majority of patients will develop a locoregional recurrence ${ }^{9}$. Many different strategies have been evaluated to improve the outcome of gastric cancer surgery. Randomized trials investigating the role of a more extended lymph node dissection (D2) in comparison with the standard D1 lymphadenectomy, found no difference in overall survival, while a D2 dissection was associated with increased postoperative mortality and morbidity ${ }^{10,13-15}$.

Two Western studies have changed current clinical practice in the treatment of resectable gastric cancer. The Intergroup 0116 study showed a significant benefit in overall survival with adjuvant chemoradiotherapy (CRT) consisting of 45 Gy of radiotherapy combined with fluorouracil (5-FU), and leucovorin, compared to surgery alone ${ }^{10}$. The phase III UK Medical Research Adjuvant Gastric Cancer Study (MAGIC) randomised 503 patients with resectable adenocarcinoma of the stomach, oesophago-gastric junction (OGJ), or lower oesophagus to either perioperative chemotherapy and surgery or surgery alone ${ }^{9}$. All patients were planned to receive three cycles of preoperative ECF (Intravenous epirubicin $50 \mathrm{mg} / \mathrm{m}^{2}$ and cisplatin $60 \mathrm{mg} / \mathrm{m}^{2}$ on day 1 , and a continuous infusion of 5-fluorouracil $200 \mathrm{mg} /$ $\mathrm{m}^{2}$ day for 21 days) chemotherapy and three cycles of the same chemotherapy after surgery. At a median follow up of 4 years, the addition of perioperative chemotherapy demonstrated a significant improvement in progressionfree survival (HR 0.66; 95\% CI, 0.53-0.81; $P<0.001$ ) and overall survival (HR, $0.75 ; 95 \% \mathrm{CI}, 0.60-0.93 ; P=$ 0.009 ; five-year survival rate, $36 \%$ vs $23 \%$ ). Importantly, the addition of preoperative chemotherapy did not increase complications from surgery and similar rates of postoperative morbidity and 30-day mortality were seen in both arms. In comparison to the surgery alone arm, a significantly higher proportion of patients treated with chemotherapy had curative resections (as deemed by the surgeon; $79.3 \%$ vs $70.3 \% ; P=0.03$ ) and were also found to have significantly smaller tumours and lower nodal burden at surgery. There was no heterogeneity of treatment effect according to the site of primary tumour (stomach, GOJ or lower oesophagus). Although 91\% of patients were able to complete 3 cycles of preoperative treatment, only $50 \%$ could complete all postoperative treatment, thereby highlighting the challenges involved in administering chemotherapy after radical gastric surgery.

In many countries neoadjuvant chemoradiotherapy is the standard of care for operable disease. The neoadjuvant therapy is used to decrease the tumour bulk and improve the rate of complete surgical clearance following resection, with the aim of improving survival and reducing risk of tumour recurrence. The evaluation of histological changes in the tumour resection specimen is a method of assessing response to neoadjuvant therapy, and there is evidence that histological response reflects on survival ${ }^{10}$. 


\section{PATIENTS AND METHODS}

\section{Patient population and Eligibility criteria:}

Twenty five patients with resectable gastric or gastroesophageal junction caner were enrolled in this study in the period between January 2012 and January 2013 with following inclusion criteria: Ib-III (no distant metastases) gastric cancer (histologically proven); tumor bulk has to be in the stomach but may involve gastro-esophageal junction, $\mathrm{WHO}<2$, age $\geq 18$ yrs, no prior abdominal radiotherapy or chemotherapy, hematology: $\mathrm{Hb} \geq 9.0 \mathrm{gm} / \mathrm{l}$; leukocytes $\geq 3.0 / \mathrm{mm}^{3}$, neutrophils $\geq 1.5 / \mathrm{mm}^{3}$, thrombocytes $\geq 100 / \mathrm{mm}^{3}$, renal function: serum creatinine $\leq 1.25$ ULN, creatinine clearance $\geq 60 \mathrm{ml} / \mathrm{min}$ (calculated by Cockcroft and Gault formula), liver function: total bilirubin $\leq 1.5 \mathrm{x}$ ULN, Alkaline phosphatase and ASAT/ALAT $\leq 3 \mathrm{x}$ ULN and Left ventricular ejection fraction $>50 \%$. While patients with the following criteria were excluded: T1N0 disease (endoscopic ultrasound), distant metastases, inoperable patients; due to technical surgery-related factors or general condition, previous malignancy, except adequately treated non-melanoma skin cancer or insitu cancer of the cervix uteri, uncontrolled infections, significant concomitant diseases preventing the safe administration of study drugs or likely to interfere with study assessments, uncontrolled angina pectoris; cardiac failure or clinically significant arrhythmias, continuous use of immunosuppressive agents, Hearing loss $>$ CTC grade 1 (In case of subjective hearing loss an audiogram is advised), Neurotoxicity $>$ CTC grade 1 and Pregnancy or breast feeding.

\section{Treatment plan:}

All patients planned to receive 3 cycles of epirubcin, cisplatin and capecitabine (ECC) at three-weekly intervals preoperatively.

\section{The chemotherapy regimen:}

Epirubicin was given in a dose of $50 \mathrm{mg} / \mathrm{m}^{2}$ diluted in $250 \mathrm{cc}$ normal saline $0.9 \%$ over half an hour on day 1 intravenously every 3 weeks immediate prior to the cisplatin.

Cisplatin was administered at a dose of $60 \mathrm{mg} / \mathrm{m}^{2}$ diluted in $1000 \mathrm{cc}$ normal saline $0.9 \%$ on day 1 intravenously every 3 weeks with good hydration.

Capecitabine was given orally in two equally divided doses, $1000 \mathrm{mg} / \mathrm{m}^{2}$ bid with a meal or snack from day 1-14 every 3 weeks.

Hydration done using $1000 \mathrm{cc}$ of normal saline $0.9 \%$ and glucose $5 \%$ to each we added $20 \mathrm{mmol} \mathrm{Kcl,} 500 \mathrm{mg}$ $\mathrm{MgSO} 4$ and $1000 \mathrm{mg}$ calcium gluconat, to be followed by $20 \mathrm{mg}$ furosemide.
All patients received standard premedication with i.v. dexamethasone $(20 \mathrm{mg})$, antihistamine, ranitidine $\mathrm{Hcl}$ (Zantac) and antiemetic treatment (ondansetron $16 \mathrm{mg}$ or granisetron $3 \mathrm{mg}$ ) 1 hour before the start of therapy.

\section{Pre-treatment assessment and Post-treatment reassessment:}

Required baseline investigations before starting treatment including: History and physical examination, Weight, length, performance status $(\mathrm{WHO})^{16}$, upper gastrointestinal tract endoscopy, representative tumor biopsy samples, in case of malnutrition placement of feeding tube, Endoscopic Ultrasonograpy (EUS), staging laparoscopy, hemoglobin, WBC and neutrophils, platelets, creatinine and creatinine clearance (calculated), Na, K, Ca, P, Bilirubin, Alk. phosphatase, ASAT, ALAT, $\gamma \mathrm{GT}$, albumin, magnesium and calcium, tumor markers (CEA, CA 19.9), CT-scan chest and abdomen and Cardiac ejection fraction. Tumor response was evaluated after the third cycle using the same evaluation methods.

\section{Toxicity: \\ Toxicity will be measured according to NCI Common Toxicity Criteria, version 3.0.}

\section{Dose adjustments for toxicity:}

Dose adjustments during treatment were made based on Absolute Neutrophil Count (ANC) and platelet counts performed within 24 hours prior to the start of therapy and clinical assessment of nonhematologic toxicities. The day-1 dose of each subsequent cycle depended on the toxicity seen in the previous cycle. The treatment was delayed until the ANC returned to 1500 and the platelet count to 100.000 . Otherwise, full doses of both drugs were given, except in patients with grade 4 neutropenia lasting $>1$ week, grade 4 neutropenia associated with fever $\geq 38.5^{\circ} \mathrm{C}$, or grade 4 thrombocytopenia. In these circumstances, after recovery, the doses of drugs were given at $75 \%$ of the dose given on day 1 . The observed nonhematologic toxicities (except alopecia and vomiting) had to return to WHO grade 0 to 1 , or baseline conditions, before resuming treatment by the drugs. Doses in subsequent cycles were reduced to $75 \%$ or held for any grade 3 nonhematologic toxicity (except nausea/vomiting and alopecia), and were reduced to $50 \%$ or held for any grade 4 nonhematologic toxicity. Patients were withdrawn from the study after 3 weeks of treatment delay due to any toxicity. If serum bilirubin was increased to $>1.5 \times \mathrm{ULN}$ or AST/ALT increased to $>3 \times \mathrm{ULN}$ in patients without liver metastasis and $>5.0 \times \mathrm{ULN}$ in patients with liver metastasis at the start of the next cycle then the cycle was delayed until serum bilirubin returned to $\leq 1.5 \times \mathrm{ULN}$ and AST/ALT returned to $\leq 3 \times \mathrm{ULN}$ in patients without liver metastasis and $\leq 5.0$ 
$\times$ ULN in patients with liver metastasis. If the values did not return to these limits within 42 days from Day 1 of the current cycle then the patient was discontinued from the study. Creatinine clearance (calculated by Cockcroft and Gault formula) prior to treatment should be more than $60 \mathrm{ml} / \mathrm{min}$. Thereafter creatinine clearance was repeated before each course of cisplatin and its dose should be adjusted as follows:

Creatinine clearance $>60 \mathrm{ml} / \mathrm{min}$ Full dose, 40-60 $\mathrm{ml} / \mathrm{min}$ Same dose of cisplatin in $\mathrm{mg}$ as the value of creatinine clearance in $\mathrm{ml} / \mathrm{min}$ (for example of $45 \mathrm{ml} / \mathrm{min}$ give $45 \mathrm{mg} / \mathrm{m}^{2}$ cisplatin), or $<40 \mathrm{ml} / \mathrm{min}$ Omit cisplatin.

\section{Surgery:}

After completion of neoadjuvant chemotherapy patients were restaged with a CT scan of the abdomen and chest. The radiological assessment of response was evaluated. In the absence of metastatic disease patients underwent partial or total gastrectomy depending upon the site of the tumor. If possible, a macroscopic proximal and distal margin of $5 \mathrm{~cm}$ was obtained.with D1-D2 lymphadenectomy with a minimum of 15 lymph nodes. Surgery was planned 3-6 weeks after the last chemotherapy course. The definitive decision to proceed to surgery was taken based on the absence of signs of progressive disease and other contraindications for surgery.

Under general anesthesia supported by epidural anesthesia, a midline laparotomy was performed, followed by a complete exploration of the abdomen including peritoneal surfaces, liver, and in women, the ovaries. Any free abdominal fluid was aspirated for cytological examination. A curative resection was not possible in case of tumor infiltration into the head of the pancreas requiring a Whipple procedure, para-aortic lymph node metastases below the renal arteries, tumor positive cytology of free peritoneal fluid, or peritoneal metastases that could not be included in the planned local resection. If curative resection was not possible, the best palliative surgical option was to be decided upon by the surgeon.

\section{Pathology:}

The specimen was sent to the pathologist, preferably fresh and unopened to enable the collection of fresh frozen tissue, followed by processing and reporting of the specimen. The pathology report included a minimal dataset containing the following items: type of tumor, localization and size of tumor, invasion depth, surgical margins, number of (tumor positive) lymph nodes and histological response criteria following neoadjuvant chemotherapy according to Ninomiya criteria.

\section{Definition of response:}

Analysis of the response to preoperative treatment was defined clinically as well as pathologically. Down

\begin{tabular}{|c|c|c|}
\hline Grade 0 & $\begin{array}{l}\text { No change } \pm \text { neither } \\
\text { necrosis nor cellular or } \\
\text { structural change can } \\
\text { be seen throughout the } \\
\text { lesion }\end{array}$ & \\
\hline & Grade 1 & $\begin{array}{l}\text { (a) Necrosis } \\
\text { disappearance of the tumour } \\
\text { is present in less than } 1 / 3 \\
\text { of the whole lesion } 1(\mathrm{~b}) \\
\text { Necrosis or disappearance of } \\
\text { the tumour is present in no } \\
\text { more than } 2 / 3 \text { of the whole } \\
\text { lesion }\end{array}$ \\
\hline & Grade 2 & $\begin{array}{l}\text { Moderate change } \pm \text { necrosis } \\
\text { or disappearance of the } \\
\text { tumour is present in more } \\
\text { than } 2 / 3 \text { of the whole lesion, } \\
\text { but viable tumour cells } \\
\text { remain. }\end{array}$ \\
\hline & Grade 3 & $\begin{array}{l}\text { Marked change } \pm \text { the whole } \\
\text { lesion falls into necrosis } \\
\text { and/or is replaced by } \\
\text { fibrosis, with or without } \\
\text { granulomatous changes. No } \\
\text { viable tumour cells. }\end{array}$ \\
\hline
\end{tabular}

staging was considered when pathological $\mathrm{T}(\mathrm{pT})$ was less than ultrasound $\mathrm{T}$ ( $\mathrm{uT}$ ) by endoscopic US or clinical $\mathrm{T}$ (cT) by CT. No response was considered when $\mathrm{pT}$ and $\mathrm{uT}$ or $\mathrm{cT}$ were similar. Disease progression was considered when $\mathrm{pT}$ was $>\mathrm{uT}$ or cT or when metastases were observed during surgery. Resected tumors were classified pathologically according to the tumor-nodemetastasis system $(\mathrm{TNM})^{18}$.

\section{Data analysis:}

Descriptive statistics were used to characterize study subjects and response to treatment. The primary end point of the study was the response rate. The toxicity was the secondary end point which was assessed as mentioned above using the NCI Common Toxicity Criteria, version 3.0.

\section{RESULTS}

Patients, clinic-pathological criteria are shown in Table (1).

\section{Toxicity and treatment adherence: Preoperative treatment:}

During preoperative treatment $100 \%$ of patients $(25$ patients) received full course of chemotherapy, while $12 \%$ of patients (3 patients) received chemotherapy with delay 1-2 weeks; one due to diarrhea grade 3, another one due to hand and foot syndrome grade 3 while the third one because of stomatitis grade 3. The toxicity observed in the 25 patients during 
the preoperative part of treatment was mainly gastrointestinal, skin, and to some extent stomatitis (Table 2 ). There was only one patient (4\%) complained of diarrhea which was grade 3 , while grades 1-2 were recorded in 3 patients $(12 \%)$. All of the patients were controlled with antidiarrheal medications and intestinal antiseptics. Hand and foot syndrome was noticed in 2 patients $(8 \%)$ and one patient $(4 \%)$ with grades 1 and 3 respectively. The main hematological toxicity was anemia with 1 patient (4\%) presented with grade 3 , while 2 patients $(8 \%)$ were grade 2 , followed by leucopenia and thrombocytopenia with 2 patients $(8 \%)$ in both toxicity.

\section{Surgery:}

Of the 25 patients that completed the preoperative treatment, 22 patients were operated upon: one patient died by sudden cardiac arrest unrelated to treatment which developed at the 4 th week after preoperative treatment, and before the scheduled surgery. Another one patient refused surgery, while in the third one, tumor progressed with development of peritoneal nodules and liver metastases made it irresectable.

Of the 22 patients, $19(86.3 \%)$ had gastric tumor while 3 patient $(13.7 \%)$ with gastroesophageal tumor. Partial gastrectomy was performed in 11 patients $(50 \%)$, while radical gastrectomy in 8 patients $(36.3 \%)$, while three patients $(13.7 \%)$ underwent partial gastrectomy with lower esophagectomy. D1 and D2 dissection were performed in 5 patients $(22.7 \%)$ and 17 patients $(77.3 \%)$ respectively. Delay in wound healing occurred in $23.8 \%$ of patients (5 patients). Pelvic abscess developed in $4.5 \%$ of patients ( 1 patient), Table (3).

\section{Efficacy: Down staging and Pathologic complete response}

Following the preoperative treatment, the pathological staging of the 22 patients operated upon according to TNM staging system is shown in Table (4).

Table 1: Clinicopathologic characteristics of study patients $(\mathrm{n}=25)$.

\begin{tabular}{|c|c|c|c|}
\hline \multicolumn{2}{|c|}{ Clinicopathologic patients characteristics } & \multirow{2}{*}{$\frac{\text { Number (25) }}{18}$} & \multirow{2}{*}{$\begin{array}{c}\text { Percentages }(\mathbf{1 0 0} \mathbf{0}) \\
72.0\end{array}$} \\
\hline & Male & & \\
\hline $\mathrm{N}$ & Female & 7 & 28.0 \\
\hline \multirow[t]{2}{*}{ Age } & Median & \multicolumn{2}{|c|}{54} \\
\hline & Range & \multicolumn{2}{|c|}{$31-72$} \\
\hline \multirow{2}{*}{ Performance status } & Zero & 15 & 60.0 \\
\hline & One & 10 & 40.0 \\
\hline \multirow{2}{*}{ Site of the tumor } & Stomach & 20 & 80.0 \\
\hline & Gastroesophageal junction & 5 & 20.0 \\
\hline \multirow{2}{*}{ Pathologic type } & Intestinal & 18 & 72.0 \\
\hline & Diffuse & 7 & 28.0 \\
\hline \multirow{2}{*}{ Grade } & Moderately differentiated & 22 & 88.0 \\
\hline & Poorly differentiated & 3 & 12.0 \\
\hline \multirow{4}{*}{ Clinical stage $(\mathrm{cTN})$} & T2 N0 & 10 & 40.0 \\
\hline & $\mathrm{T} 2 \mathrm{~N}+$ & 10 & 40.0 \\
\hline & T3 N0 & 3 & 12.0 \\
\hline & $\mathrm{T} 3 \mathrm{~N}+$ & 2 & 8.0 \\
\hline \multirow[t]{2}{*}{$\mathrm{cT}$} & $\mathrm{T} 2$ & 20 & 80.0 \\
\hline & T3 & 5 & 20.0 \\
\hline \multirow[t]{2}{*}{$\mathrm{cN}$} & N0 & 13 & 52.0 \\
\hline & $\mathrm{N}+$ & 12 & 48.0 \\
\hline
\end{tabular}


Kasr-El-Aini Journal Of Clinical Oncology And Nuclear Medicine

Vol. 9 | No. 3-4 2013

Mohamed El. Bassiouny et al.

Table 2: Description of neoadjuvant treatment related complication among study patients.

\begin{tabular}{|c|c|c|c|c|c|c|c|c|c|c|}
\hline \multirow[t]{2}{*}{ Toxicity } & \multicolumn{2}{|c|}{ Grade 1} & \multicolumn{2}{|c|}{ Grade 2} & \multicolumn{2}{|c|}{ Grade 3} & \multicolumn{2}{|c|}{ Grade 4} & \multicolumn{2}{|c|}{ G 3-4 } \\
\hline & $\begin{array}{c}\text { No of } \\
\text { patients }\end{array}$ & $\%$ & $\begin{array}{c}\text { No of } \\
\text { patients }\end{array}$ & $\%$ & $\begin{array}{c}\text { No of } \\
\text { patients }\end{array}$ & $\%$ & $\begin{array}{c}\text { No of } \\
\text { patients }\end{array}$ & $\%$ & $\begin{array}{c}\text { No of } \\
\text { patients }\end{array}$ & $\%$ \\
\hline Anemia & - & - & 2 & 8 & 1 & 4 & - & - & 1 & 4 \\
\hline Leucopenia & - & - & 2 & 8 & - & & - & - & - & - \\
\hline thrombocytopenia & 1 & 4 & 1 & 4 & - & - & - & - & - & - \\
\hline Diarrhea & 1 & 4 & 2 & 8 & 1 & 4 & - & - & 1 & 4 \\
\hline Nausea & - & - & 4 & 16 & 4 & 16 & - & - & 4 & 16 \\
\hline Vomiting & - & - & 3 & 12 & 3 & 12 & - & - & 3 & 12 \\
\hline Hand and foot syndrome & 2 & 8 & - & - & 1 & 4 & - & - & 1 & 4 \\
\hline stomatitis & 2 & 8 & - & - & 1 & 4 & - & - & 1 & 4 \\
\hline
\end{tabular}

Table 3: Description of surgical treatment and its related complication among study patients (22 patients).

\begin{tabular}{lccc}
\hline $\begin{array}{l}\text { Description of } \\
\text { study patients }\end{array}$ & Radical gastrectomy & 8 & 36.3 \\
\hline \multirow{2}{*}{ Surgery } & Partial gastrectomy & 11 & 50 \\
\cline { 2 - 4 } & $\begin{array}{c}\text { Partial gastrectomy } \\
\text { with esophagectomy }\end{array}$ & 3 & 13.7 \\
\hline \multirow{2}{*}{ Lymphadenectomy } & D1 & 5 & 22.7 \\
\cline { 2 - 4 } & D2 & 17 & 77.3 \\
\hline Surgical complications & & $\mathrm{N}(22)$ & $\%$ \\
\hline Delayed wound healing & & 2 & 9 \\
\hline Intestinal obstruction & & 1 & 4.5 \\
\hline Burst abdomen & & 1 & 4.5 \\
\hline
\end{tabular}

Table 4: Description of postoperative data of study patients

\begin{tabular}{|c|c|c|c|}
\hline $\begin{array}{l}\text { Description of postoper } \\
\text { study patients }\end{array}$ & data of & $\mathbf{N}(22)$ & $\%$ \\
\hline \multirow{7}{*}{ Pathological stage (pTN) } & pT0 N1 & 2 & 9 \\
\hline & pT0 N2 & 1 & 4.5 \\
\hline & pT1 N0 & 5 & 22.7 \\
\hline & pT1 N1 & 4 & 18.1 \\
\hline & $\mathrm{pT} 2 \mathrm{~N} 0$ & 2 & 9 \\
\hline & pT2 N1 & 4 & 18.1 \\
\hline & pT3 N2 & 4 & 18.1 \\
\hline \multirow{4}{*}{ pT } & pT0 & 3 & 13.6 \\
\hline & pT1 & 9 & 40.9 \\
\hline & pT2 & 6 & 27.2 \\
\hline & pT3 & 4 & 18.1 \\
\hline \multirow{3}{*}{$\mathrm{pN}$} & $\mathrm{pN} 0$ & 7 & 31.8 \\
\hline & $\mathrm{pN} 1$ & 10 & 45.4 \\
\hline & $\mathrm{pN} 2$ & 5 & 22.7 \\
\hline Complete response & & 3 & 13.6 \\
\hline Down staging & & 10 & 45.4 \\
\hline Stationary disease & & 9 & 40.9 \\
\hline
\end{tabular}

\section{DISCUSSION}

Gastric cancer remains to be an important health issue worldwide. Over the past two decades, the incidence of distal gastric cancer has been decreased, but the incidence of proximal and esophagogastric junction cancers has been increased significantly ${ }^{19}$. The treatment of the gastroesophageal and gastric cancer is dependent on the TMN staging of the tumor. The advanced gastroesophagealand gastric cancers (stage III-IVB) without evidence of distant metastasis are potentially curable, but these tumors usually present with a more advanced stage and are associated with a worse prognosis ${ }^{20}$, and a combination therapy, including surgery, chemotherapy and radiotherapy, is often needed. Chemotherapy is an adjuvant treatment modality in the form of adjuvant chemotherapy, NAC and concomitant chemoradiotherapy [21]. NAC has several advantages: (1) it is well tolerated; (2) it can better control the micrometastasis ${ }^{22}$; and (3) it might downstage the tumor to the greatest extent and increase the probability of $\mathrm{R} 0$ resection so as to facilitate the surgery ${ }^{23}$, thus improving the survival rate of the patients with gastroesophageal and gastric cancer. However, it might delay the curative treatment if the tumor does not respond to the NAC, which is also costly and may be detrimental to the patients. Theoretically, NAC can increase the survival rate and improve the quality of life of the patients.

Complete surgical resection of gastric cancer with negative margin (that is, $\mathrm{R} 0$ resection) is the most effective treatment to date and is related to better outcome. Unfortunately, many gastric cancer patients admitted to hospital are at an advanced stage and unresectable. Strategies to increase the R0 resection rate and overall survival could include both early detection and downstaging of the lesions. Early detection has proved to be useful in Japan, which 
leads to a large proportion of early stage lesions and better survival outcome. However, in countries with relatively low incidence of gastric cancer, large scale screening may be not cost effective. Despite much effort to treat advanced gastric cancer, such as extended lymphadenectomy, it has proved difficult to achieve much toward the goal of improved treatment leading to better patient outcome ${ }^{24}$.

Although it is generally agreed that patients with inoperable tumours have a poorer prognosis than those who are resectable, some degree of controversy does exist. That is, that surgical resection, whether curative or not, may be associated with a longer survival and removes the risk of potential complications. In the West it is generally considered by that palliative resection is indicated for primarily obstruction, bleeding, and less frequently perforation. They also found that gastrectomy appeared to be linked with a better survival. Sasako stated that even for linitis plastica that donot cause obstruction, survival of resected patients was superior to that of non-resected (Sasako 1996) ${ }^{25}$. Consequently, to downstage the tumor and improve $\mathrm{R} 0$ rate should be the primary goals, and to achieve this for gastric cancer, neoadjuvant chemotherapy may be a potential effective therapeutic strategy.

Neoadjuvant chemotherapy has achieved great success in the management of breast cancer, osteosarcoma, rectal cancer, and other malignancies such as cervical cancer. In fact, neoadjuvant chemotherapy of gastric cancer was first attempted some time ago, the first report being published in 1967 (Fujimoto 1969) ${ }^{26}$. These data were updated later, in 1976 (Fujimoto 1976) ${ }^{27}$. The study was later neglected because of high toxicity and low response rate. Another factor is that gastric adenocarcinoma is only moderately sensitive to cytotoxic agents such as 5-fluoracil, metrometrate, mitomycin, and cisplatin. However, even with continuing efforts made by surgeons, oncologists, and biomedical professionals, the outcome of gastric cancer has not demonstrated a great improvement for decades, especially for those in the advanced stages of the disease. Patients with locally advanced disease who have undergone an $\mathrm{R} 0$ resection constitute the best prognostic group, with an estimated 5-year survival of $25 \%$ in Western countries and approximately $30 \%$ in Japan. However, even in patients who have a curative resection, nearly two thirds suffer from local recurrence and distant metastasis.

Many studies have been performed with adjuvant chemotherapy in resectable gastric cancer. These studies have been part of several meta-analyses, which could demonstrate no, or at the most a modest survival benefit for adjuvant chemotherapy ${ }^{28-33}$. Newer chemotherapy schedules, with capecitabine and oxaliplatin, have shown to be as least as effective as schedules with 5-FU and cisplatin, with respect to overall survival (REAL-2 study) $)^{34}$.

The combination of adjuvant with neo-adjuvant chemotherapy has proven its value in two randomized studies. In the MAGIC study, perioperative chemotherapy resulted in a reduction of the tumour stage, a $10 \%$ higher resectability rate and a significant survival benefit of $13 \%$ at 5 years ${ }^{9}$. It should be noted that only $55 \%$ started postoperative chemotherapy and $42 \%$ of the patients completed the entire treatment. The major reasons for a premature treatment stop were tumour progression, postoperative complications, patients' refusal and toxicity. A French prospective trial showed comparable results with $48 \%$ of the patients completing the total regimen ${ }^{12}$. The final report of this study has to be awaited.

Due to the strong position of perioperative chemotherapy with tumour downsizing and downstaging the CRITICS investigators were reluctant towards a randomization arm without preoperative chemotherapy. Therefore, both arms have the same preoperative chemotherapy schedule. This also leads to comparable resection rates thus eliminating the effect of surgery (and preoperative therapy) on a potential survival difference between the two treatment arms ${ }^{35}$.

In our study we enrolled 25 patients with median age 54 years, with $60 \%$ of patients were PS WHO 0 , $80 \%$ of tumors gastric in location, while $20 \%$ were in the gastroesophageal junction, most cases were stage 2 with $48 \%$ with positive lymph nodes. These patients characters were comparable with both MAGIC and CRITICS studies ${ }^{9,35}$.

We recorded ORR 59\% (13/22 patients); where 3/22 patients (13.6\%) attained CR; 10/22 patients (45.4\%) attained PR. Stable disease (SD) occurred in $9 / 22$ patients and 1 patient had PD. These response rates are almost similar to that reported in the studies conducted by Cunningham and his colleagues and Dikken and his co-workers. In view of previously shown data PCR rate of $13.6 \%$ (3/22) was encountered. By comparing clinical $\mathrm{T}$ stage and pathological $\mathrm{T}$ stage down staging was found to be $45.4 \%(10 / 22)$ and no disease progression was observed in any of the operated patients. This pathological staging response confirmed by Niomiya grading, with patients with complete response were grade 3 , while patients with down staging (partial response) were grades 1 and 2. Patients with stationary disease were grade 0 .

The toxic effects of the combination chemotherapy in the present study were manageable and consisted 
mainly of non-hematological toxicities. The toxicity observed in the 25 patients during the preoperative part of treatment was mainly gastrointestinal, skin, and to some extent stomatitis (table 2). Patients complained of diarrhea were one patient (4\%) with grade 3 , while 3 patients $(12 \%)$ were gradewere grades $1 / 2$. Hand and foot syndrome was noticed in 2 patients $(8 \%)$ and in one patient (4\%) with grades 1 and 3 , respectively. The main hematological toxicity recorded was anemia with 1 patient $(4 \%)$ with grade 3 , while 2 patients $(8 \%)$ were grade 2 , followed by leucopenia and thrombocytopenia with 2 patients $(8 \%)$ in each toxicity. While Cunningham and his colleagues ${ }^{9}$ documented that both hematological and non-hematological toxicities were similar with leucopenia grades $1 / 2$ occurred in $88.5 \%$ and grades 3 or $411.5 \%$, anemia grades $1 / 2$ documented in $95.3 \%$ and grades 3 or $40.4 \%$. Diarrhea as grades $1 / 2$ documented in $97.4 \%$, and as grades 3 or $42.6 \%$; while stomatitis documented as $95.7 \%$ and $4.3 \%$ as grades $1 / 2$ and $3 / 4$, respectively.

\section{CONCLUSION}

In conclusion, Epirubcin in combination with cisplatin and capecitabine has demonstrated an acceptable activity as well as tolerable safety profile. Further evaluation of this regimen is warranted in the management of patients with operable gastric and gastroesophageal junction cancer as neoadjuvant.

\section{REFERENCES}

1. Ferlay J, Shin HR, Bray F, Forman D, Mathers C, Parkin DM. Estimates of worldwide burden of cancer in 2008: GLOBOCAN 2008. Int.J.Cancer 2010;127(12):289328917.

2. CRC. Cancer Research Uk, CancerStats-Key Facts, London, UK, 2009.

3. Dolan K, Sutton R, Walker SJ, Morris A, Campbell F, Williams EM. New classification of oesophageal and gastric carcinomas derived from changinq patterns in epidemiology. Br.J.Cancer 1999;80(5-6):834-42 .

4. Lagergren J, Bergström R, Lindgren A, Nyrén O. Symptomatic gastroesophageal reflux as a risk factor for esophageal adenocarcinoma. N.Engl.J.Med. 1999;340(11):825-31.

5. Botterweck AA, Schouten LJ, Volovics A, Dorant E, van Den Brandt PA. Trends in incidence of adenocarcinoma of the oesophagus and gastric cardia in ten European countries. Int.J.Epidemiol. 2000;29(4):645-54.

6. Nashimoto A, Nakajima T, Furukawa H, Kitamura M, Kinoshita T, Yamamura Y, et al. Randomized trial of adjuvant chemotherapy with mitomycin, Fluorouracil, and Cytosine arabinoside followed by oral Fluorouracil in serosa-negative gastric cancer: Japan Clinical Oncology Group 9206-1. J.Clin.Oncol. 2003;21(12):2282-7.
7. International Agency for Research on Cancer. GLOBOCAN 2008: Cancer Incidence and Mortality Worldwide.2010International Agency for Research on Cancer, .

8. Inoue M, Tsugane S. Epidemiology of gastric cancer in Japan. Postgrad Med.J. 2005;81(957):419-24.

9. Cunningham D, Allum WH, Stenning SP, Thompson JN, Van de Velde CJ, Nicolson M, et al. Perioperative chemotherapy versus surgery alone for resectable gastroesophageal cancer. N.Engl.J.Med. 2006;355(1):11-20.

10. Macdonald JS, Smalley SR, Benedetti J, Hundahl SA, Estes NC, Stemmermann GN, et al. Chemoradiotherapy after surgery compared with surgery alone for adenocarcinoma of the stomach or gastroesophageal junction. N.Engl.J.Med. 2001;345(10):725-30.

11. Biffi R, Fazio N, Luca F, Chiappa A, Andreoni B, Zampino MG, et al. Surgical outcome after docetaxelbased neoadjuvant chemotherapy in locally-advanced gastric cancer. World J.Gastroenterol. 2010;16(7):868-74.

12. Schuhmacher C, Gretschel S, Lordick F, Reichardt P, Hohenberger W, Eisenberger CF, et al. Neoadjuvant chemotherapy compared with surgery alone for locally advanced cancer of the stomach and cardia: European Organisation for Research and Treatment of Cancer randomized trial 40954. J.Clin.Oncol. 2010;28(35):5210-8.

13. Cuschieri A, Weeden S, Fielding J, Bancewicz J, Craven $\mathrm{J}$, Joypaul V, et al. Patient survival after D1 and D2 resections for gastric cancer: Long-term results of the MRC randomized surgical trial. Surgical Co-operative Group. Br.J.Cancer 1999;79(9-10):1522-30.

14. Bonenkamp JJ, Hermans J, Sasako M, van de Velde CJ, Welvaart K, Songun I, et al. Extended lymphnode dissection for gastric cancer. N.Engl.J.Med. 1999;340(12):908-14.

15. Hartgrink HH, van de Velde CJ, Putter H, Bonenkamp JJ, Klein Kranenbarg E, Songun I, et al. Extended lymph node dissection for gastric cancer: Who may benefit? Final results of the randomized Dutch gastric cancer group trial. J.Clin.Oncol. 2004;22(11):2069-77.

16. Oken MM, Creech RH, Tormey DC, Horton J, Davis TE, McFadden ET, et al. Toxicity and response criteria of the Eastern Cooperative Oncology Group. Am.J.Clin.Oncol. 1982;5(6):649-55.

17. Greene FL, Page D and Morrow M. AJCC Cancer Staging Manual.2002Springer, New York.

18. Pera M. Epidemiology of esophageal cancer, especially adenocarcinoma of the esophagus and esophagogastric junction. Recent Results Cancer Res. 2000;155:1-14.

19. Kim DY, Joo JK, Park YK, Ryu SY, Kim YJ, Kim SK. Predictors of long-term survival in node-positive gastric carcinoma patients with curative resection. Langenbecks Arch.Surg. 2007;392(2):131-4.

20. Menges M, Hoehler T. Current strategies in systemic treatment of gastric cancer and cancer of the gastroesophageal junction. J.Cancer Res.Clin.Oncol. 2009; 135(1):29-38. 
21. Bölke E, Peiper M, Knoefel WT, Baldus SE, Schauer M, Matuschek C, et al. [Multimodal therapy in locally advanced gastric cancer].[Article in German]. Dtsch.Med. Wochenschr. 2011;136(43):2205-11.

22. Zhou DL, Zheng CZ, Li JH, Yin K, Ke CW, Liu HT, et al. [Application of neoadjuvant chemotherapy in laparoscopic gastrectomy for advanced gastric cancer]. [Article in Chinese]. Zhonghua Wei Chang Wai Ke Za Zhi 2009;12(2):126-9.

23. Urschel JD, Vasan H, Blewett CJ. A meta-analysis of randomized controlled trials that compared neoadjuvant chemotherapy and surgery to surgery alone for resectable esophageal cancer. Am.J.Surg. 2002;183(3):274-9.

24. Sasako M, Maruyama K, Katai H. Is palliative gastrectomy for linitis plastica effective? Gastroenterol. Surg. 1996;19:1445-52.

25. Fujimoto S, Watanabe Y, Enomoto K, Adachi M, Itoh K. Studies on preoperative cancer chemotherapy. Methods of preoperative intra-arterial infusion by the use of methotrexate or vinblastine. Cancer 1969;24(3):433-41.

26. Fujimoto S, Akao T, Itol B, Koshizuka I, Koyano K. A study of survival in patients with stomach cancer treated by a combination of preoperative intra-arterial infusion therapy and surgery. Cancer 1976;37(4):1648-53.

27. Earle CC, Maroun JA. Adjuvant chemotherapy after curative resection for gastric cancer in non-Asian patients: Revisiting a meta-analysis of randomised trials. Eur.J.Cancer 1999;35(7):1059-64.

28. Hermans J, Bonenkamp JJ, Boon MC, Bunt AM, Ohyama S, Sasako M, et al. Adjuvant therapy after curative resection for gastric cancer: Meta-analysis of randomized trials. J.Clin.Oncol. 1993;11(8):1441-7.
29. Janunger KG, Hafström L, Glimelius B. Chemotherapy in gastric cancer: A review and updated meta-analysis. Eur.J.Surg. 2002;168(11):597-608.

30. Mari E, Floriani I, Tinazzi A, Buda A, Belfiglio M, Valentini M, et al. Efficacy of adjuvant chemotherapy after curative resection for gastric cancer: A meta-analysis of published randomised trials. A study of the GISCAD (Gruppo Italiano per lo Studio dei Carcinomi dell'Apparato Digerente). Ann.Oncol. 2000;11(7):837-43.

31. Panzini I, Gianni L, Fattori PP, Tassinari D, Imola M, Fabbri $\mathrm{P}$, et al. Adjuvant chemotherapy in gastric cancer: A meta-analysis of randomized trials and a comparison with previous meta-analyses. Tumori 2002;88(1):21-7.

32. Sun P, Xiang JB, Chen ZY. Meta-analysis of adjuvant chemotherapy after radical surgery for advanced gastric cancer. Br.J.Surg. 2009;96(1):26-33.

33. Cunningham $\mathrm{D}$, Starling $\mathrm{N}$, Rao $\mathrm{S}$, Iveson $\mathrm{T}$, Nicolson M, Coxon F, et al. Capecitabine and oxaliplatin for advanced esophagogastric cancer. N.Engl.J.Med. 2008;358(1):36-46.

34. Boige V, Pignon J, Saint-Aubert B, et al. Final results of a randomized trial comparing preoperative 5-fluorouracil (F)/cisplatin (P) to surgery alone in adenocarcinoma of stomach and lower esophagus (ASLE): FNLCC ACCORD07-FFCD 9703 trial.2007ASCO Annual Meeting Proceedings (Post-Meeting Edition)., .

35. Dikken JL, van Sandick JW, Maurits Swellengrebel HA, Lind PA, Putter H, Jansen EP, et al. Neo-adjuvant chemotherapy followed by surgery and chemotherapy or by surgery and chemoradiotherapy for patients with resectable gastric cancer (CRITICS). BMC Cancer 2011;11:329. 